\title{
Extracellular proteins as a potential marker of active Staphylococcus aureus infection in bone
}

\author{
S. J. KRIKLER and P. A. LAMBERT*
}

Royal Orthopaedic Hospital, Birmingham B31 2AP and * Pharmaceutical Sciences Institute, Department of Pharmaceutical Sciences, Aston University, Birmingham B4 7ET

\begin{abstract}
Summary. The potential of extracellular protein antigens of Staphylococcus aureus as markers of infection of bone was investigated by immunoblotting. Serum from patients with $S$. aureus bone infection showed levels of IgG antibodies to a preparation of soluble extracellular proteins of 17-81 kDa which were significantly higher than those found in serum from normal controls. By contrast, immunoblots of various whole cell or cell wall-derived antigens gave complex patterns of response which were unsuitable for positive diagnosis of $S$. aureus bone infection.
\end{abstract}

\section{Introduction}

Previous studies have shown that the antibody pattern to the major Staphylococcus aureus cell-wall antigens during active infection response is not significantly different from that found in healthy blood donors. ${ }^{1}$ Therefore, it appears that antigens such as peptidoglycan and its peptide epitopes, wall and membrane teichoic acids, are of little value as serodiagnostic markers of infection. Surface protein antigens might be important in defining host immune response to $S$. aureus infection ${ }^{2}$ and immunoblotting studies have demonstrated responses to a range of surface proteins in animal models of $S$. aureus osteomyelitis. ${ }^{3,4}$ However, the antibody response to surface proteins as shown by immunoblotting is extremely complex and currently no specific surface protein antigens with serodiagnostic potential have been identified. Comparatively little attention has been paid to extracellular antigens, despite their recognised role in staphylococcal pathogenicity. ${ }^{5}$ Earlier immunoblotting studies showed the presence of important antigens in culture supernates. ${ }^{6} \mathrm{We}$ investigated responses in patients to extracellular proteins of $S$. aureus, to evaluate their serodiagnostic potential in $S$. aureus bone infection.

\section{Materials and methods}

\section{Strains}

Five strains of $S$. aureus were used: NCTC 6571 (Oxford strain); two isolates from bone infection (A and $B$ ) and two from endocarditis (C and D).

\section{Growth and preparation of antigen fractions}

Cultures were grown in $100 \mathrm{ml}$ of Tryptic Soya Broth (TSB; Difco) for $18 \mathrm{~h}$ at $37^{\circ} \mathrm{C}$ with vigorous shaking in a rotary incubator. Cells were harvested by centrifugation $(10000 \mathrm{~g}, 10 \mathrm{~min})$ and the culture supernates were retained for the study of extracellular antigens. After washing once in saline, cell pellets were resuspended in $2 \mathrm{ml}$ of water. A $20-\mu \mathrm{l}$ volume of a freshly prepared solution of lysostaphin $(20 \mu \mathrm{g} / \mathrm{ml}$ in water; Sigma) was added and the suspensions were incubated for $2 \mathrm{~h}$ at $37^{\circ} \mathrm{C}$. Pronounced lysis was achieved for all strains as indicated by a fall in absorbance at $470 \mathrm{~nm}$ of c. $80 \%$. Remaining unbroken cells were removed by centrifugation $(5000 \mathrm{~g}$, $10 \mathrm{~min})$. The viscosity of the supernates was reduced by the addition of $20 \mu \mathrm{l}$ of RNAase solution $(1 \mathrm{mg} / \mathrm{ml}$; type I-AS, Sigma) and $20 \mu \mathrm{l}$ of DNAase solution $(1 \mathrm{mg} / \mathrm{ml}$; type I, DN-25 Sigma) and incubation for $30 \mathrm{~min}$ at $37^{\circ} \mathrm{C}$. Suspensions were then centrifuged for $1 \mathrm{~h}$ at $35000 \mathrm{~g}$ to deposit a pellet of cytoplasmic membrane material that was resuspended in $0.2 \mathrm{ml}$ of water. The supernate contained cytoplasmic material and cell-wall components solubilised by lysostaphin. All fractions were stored at $-20^{\circ} \mathrm{C}$.

\section{Antisera}

Washed whole cells of strain NCTC 6751 grown in TSB as described above were suspended in normal saline to an absorbance of 1.0 at $470 \mathrm{~nm}$. To preserve antigenic determinants, the cells were killed by exposing the suspension to UV light for $10 \mathrm{~min}$ in a thin film in a plastic tray. Two rabbits ( $3 \mathrm{~kg}$, half-lop) were given, at weekly intervals, $1 \mathrm{ml}$ of the UV-killed wholecell suspension by subcutaneous injection at three sites in the neck. After 8 weeks, blood was obtained by cardiac puncture; serum was stored at $-20^{\circ} \mathrm{C}$. 


\section{Human serum}

Serum was collected by venepuncture from five healthy adults and from patients with various staphylococcal infection and stored at $-20^{\circ} \mathrm{C}$.

\section{Immunoblotting}

SDS-PAGE was performed with $12 \%$ gels $^{7}$ in Mini Protean II (BioRad) equipment. Gels were either stained with Coomassie Blue to reveal proteins or were subjected to immunoblotting to transfer antigens to nitrocellulose sheets $(0.45 \mu \mathrm{m}$ pore size; BioRad). Electrophoretic transfer was done at $100 \mathrm{~V}$ for $1 \mathrm{~h}$ in Tris-glycine buffer $(25 \mathrm{~mm}$ Tris, $192 \mathrm{~mm}$ glycine, $\mathrm{pH} 8.3$ ) containing methanol $20 \% \mathrm{v} / \mathrm{v}$ with the Mini Trans Blot system (BioRad). Tris-buffered saline (TBS; $0.01 \mathrm{M}$ Tris- $\mathrm{HCl}, \mathrm{pH} 7.4, \mathrm{NaCl} 0.9 \% \mathrm{w} / \mathrm{v}$ ) containing Tween-20 $0.3 \% \mathrm{v} / \mathrm{v}$ was used to block unbound sites on the nitrocellulose sheets $(1 \mathrm{~h})$. The sheets were probed with sera diluted 1 in 50 in TBSTween with gentle shaking for $3 \mathrm{~h}$ at $35^{\circ} \mathrm{C}$. After being washed three times in TBS, bound IgG on the sheets was detected by its reaction with protein A-horseradish peroxidase conjugate $(50 \mu \mathrm{g} / \mathrm{ml}$ in TBS-Tween; Sigma) for $2 \mathrm{~h}$ at $25^{\circ} \mathrm{C}$. After being rinsed three times in TBS, the blots were visualised by addition of a solution containing $\mathrm{H}_{2} \mathrm{O}_{2} \quad 0 \cdot 1 \% \mathrm{v} / \mathrm{v}$ and 4-chloronaphthol $25 \mu \mathrm{g} / \mathrm{ml}$ in $0.01 \mathrm{M}$ Tris- $\mathrm{HCl}, \mathrm{pH} \mathrm{7.4}$. To determine antibody titres to individual antigens on the nitrocellulose sheets, a single sample was applied to the SDS-PAGE gel with a $10 \mathrm{~cm}$ wide single slot comb. After electrophoretic transfer and blocking with TBSTween, the nitrocellulose sheet was cut into $0.5-\mathrm{cm}$ vertical strips. Individual strips were then allowed to react with various dilutions of antisera and visualised with conjugate and 4-chloronaphthol as before.

\section{Results}

\section{Protein profiles of organisms and culture supernates}

Fig. 1 shows the protein profiles of the different preparations from each strain. Tracks containing

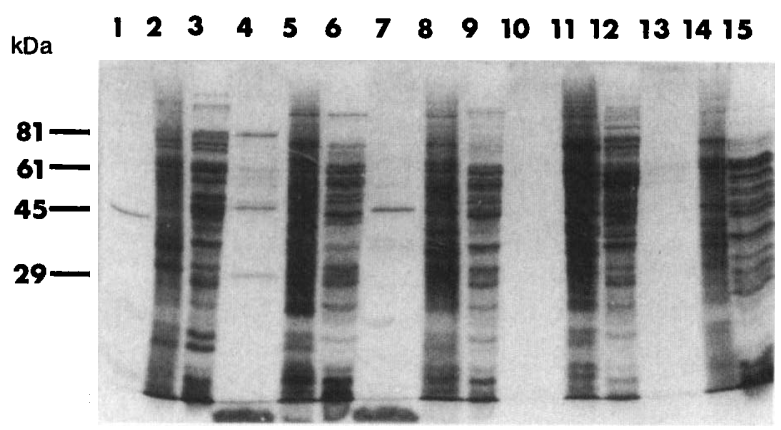

Fig. 1. Coomassie Blue-stained SDS-PAGE gel of culture supernates, cytoplasmic membranes and cytoplasm + cell-wall antigens of five strains of $S$. aureus: tracks 1-3, NCTC $6571 ; 4-6$, strain A; 7-9, strain B; 10-12, strain C; and 13-15, strain D. For each strain the samples are loaded in the order: culture supernate (tracks 1,4 , $7,10,13$ ), cytoplasmic membranes (tracks $2,5,8,11,14$ ), cytoplasm + cell-wall antigens (tracks 3, 6, 9, 12, 15). Samples were denatured for $10 \mathrm{~min}$ at $100^{\circ} \mathrm{C}$ with an equal volume of denaturing buffer and $10 \mu \mathrm{l}$ was then loaded in each track. cytoplasmic membranes or cytoplasm plus lysostaphin-solubilised wall material showed a large number of bands on staining with Coomassie Blue. No major differences were evident between the strains. Tracks containing culture supernates showed few bands but the patterns were different for each organism. Strain A contained the greatest number of bands, the most prominent running at $81 \mathrm{kDa}$ with lighter stained bands at 61,45 and $29 \mathrm{kDa}$. By contrast, strain E produced virtually no detectable extracellular protein.

\section{Antigen profiles of organisms and culture supernates}

Fig. 2 shows the antibody response to the profiles revealed by immunoblotting of the samples shown in fig. 1. Nitrocellulose sheets containing the antigen profiles were probed with antisera (diluted 1 in 50) raised in a rabbit to killed whole cells of the reference strain, NCTC 6571 (fig. 2A). Pre-immune rabbit serum and blots probed with conjugate alone gave no detectable bands. The rabbit anti-whole-cell serum contained IgG that recognised numerous antigens in the three preparations from all the strains. The antigenic profiles for the membrane and cytoplasmwall preparations were essentially the same for all strains. However, a noticeable feature of the responses to the extracellular proteins was that, while the total amount of extracellular material was low compared with the cytoplasmic and wall preparations (as shown by Coomassie Blue staining), antibody binding was readily detectable. Detection of extracellular antigens in fig. 2A was surprising because the antiserum was raised against washed UV-killed whole cells. Presumably there was some extracellular antigen associated with the cells.

Identical blots probed with human serum from five healthy donors (fig. 2B) and sera from various patients with $S$. aureus infections are shown in fig. 2C-D. The human sera showed a complex pattern of antibody response to the panel of antigens and there was no clear-cut distinction between sera from the healthy donors and the patients with staphylococcal infections. The preparation which appeared to offer the greatest discrimination between sera was the extracellular antigen preparation from strain A. Prominent antigen bands were detected at 29, 45, 61 and $81 \mathrm{kDa}$. To investigate whether this material might be of value in serodiagnosis, strip blots were probed with increasing dilutions of sera. The results are shown in fig. 3. Response with the pooled normal serum was weak and virtually undetectable at dilutions above 1 in 400 (fig. 3A). By contrast, the four patients with $S$. aureus infections gave a strong response detectable on the blots at dilutions of 1 in 800 and above (fig. 3B-E). A notable feature is the wide range of antigens detected by some sera, over 10 separate bands being detected in fig. 3B and E. All the patients with $S$. aureus bone infection (fig. 3B-C) gave a strong response to the 29$\mathrm{kDa}$ antigen band which was detected only weakly by 

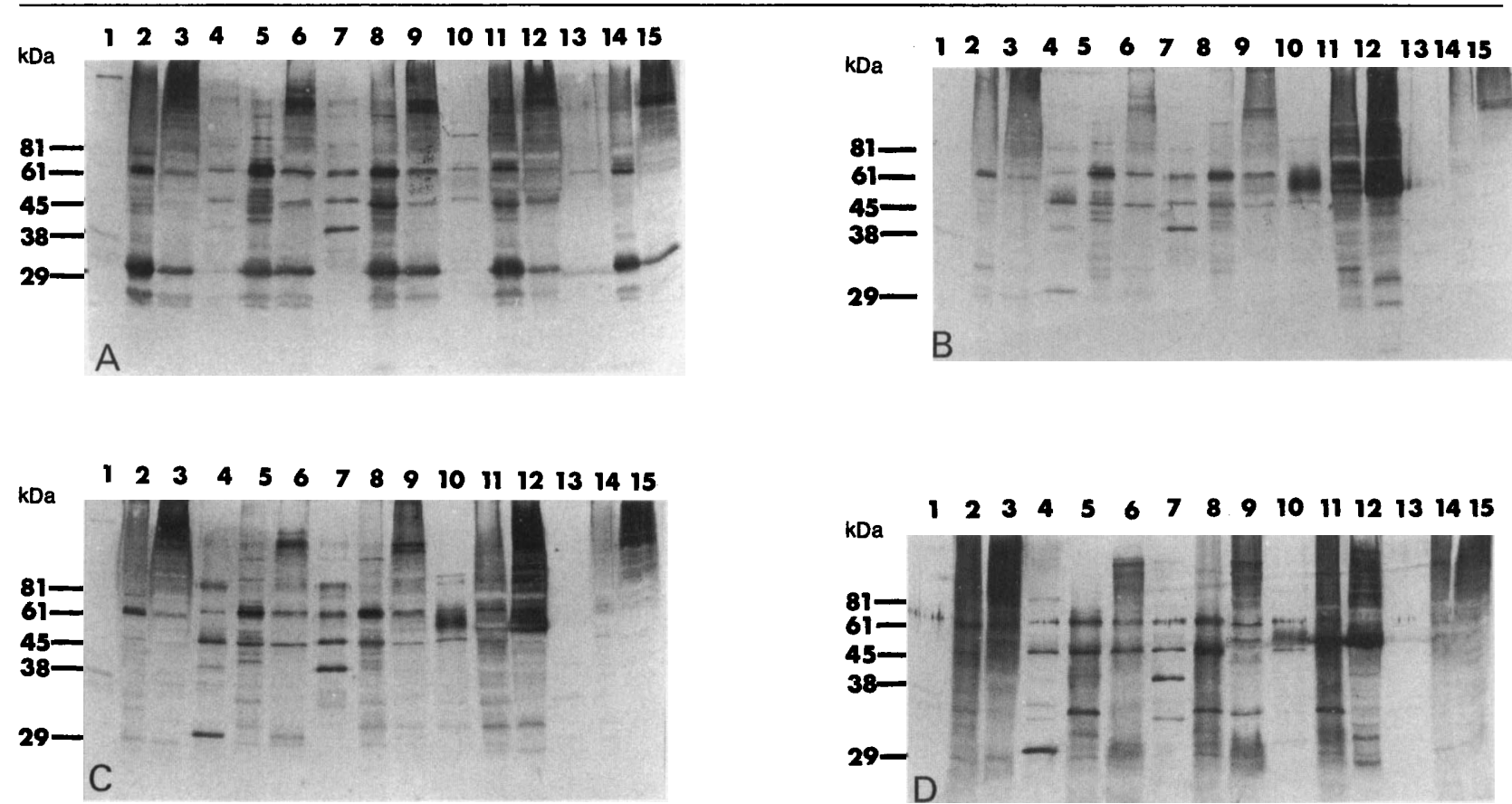

Fig. 2. Immunoblotting of the gels shown in fig. 1. Blots were allowed to react with the following sera at a dilution of 1 in 50: $\mathbf{A}$, rabbit serum raised against UV-killed whole cells of NCTC 6571 ; B, pooled serum from five healthy donors; C, patient with $S$. aureus osteomyelitis; and D, patient with infected hip prosthesis.

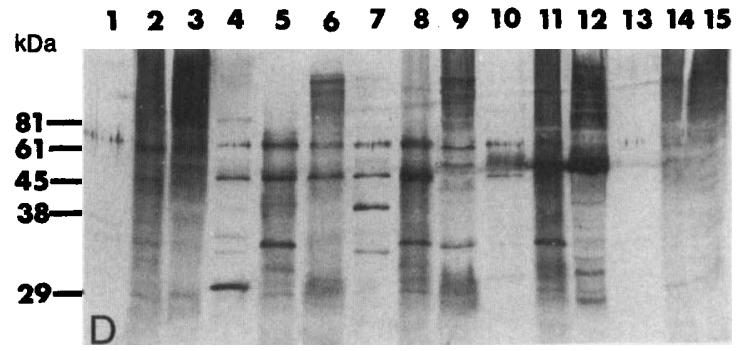

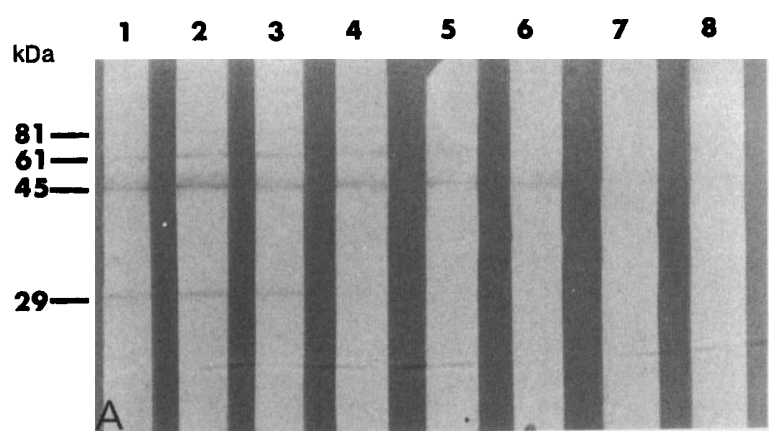
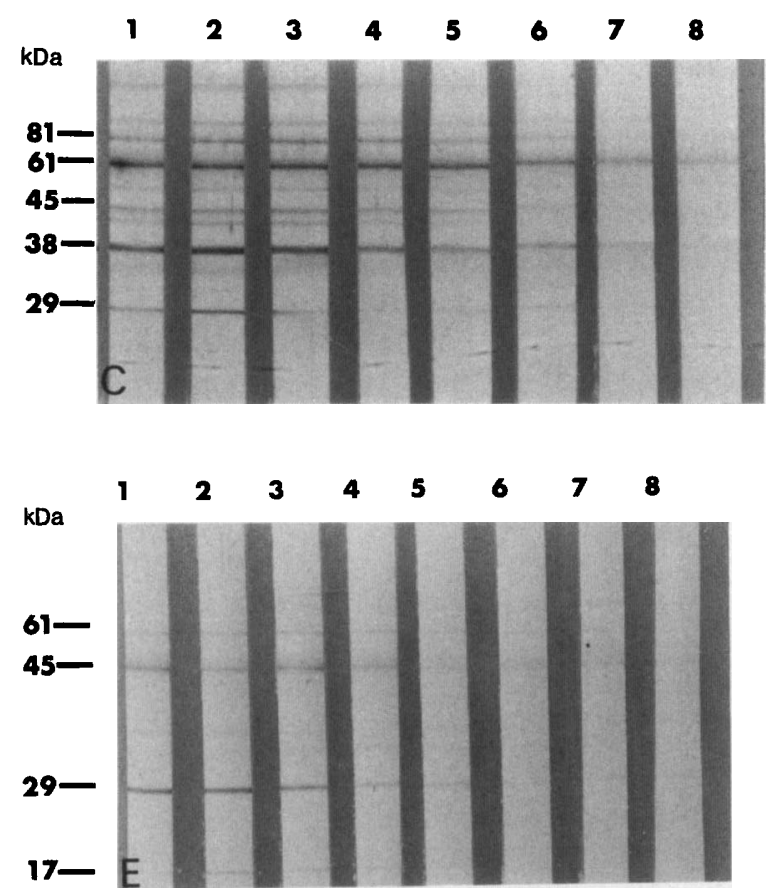
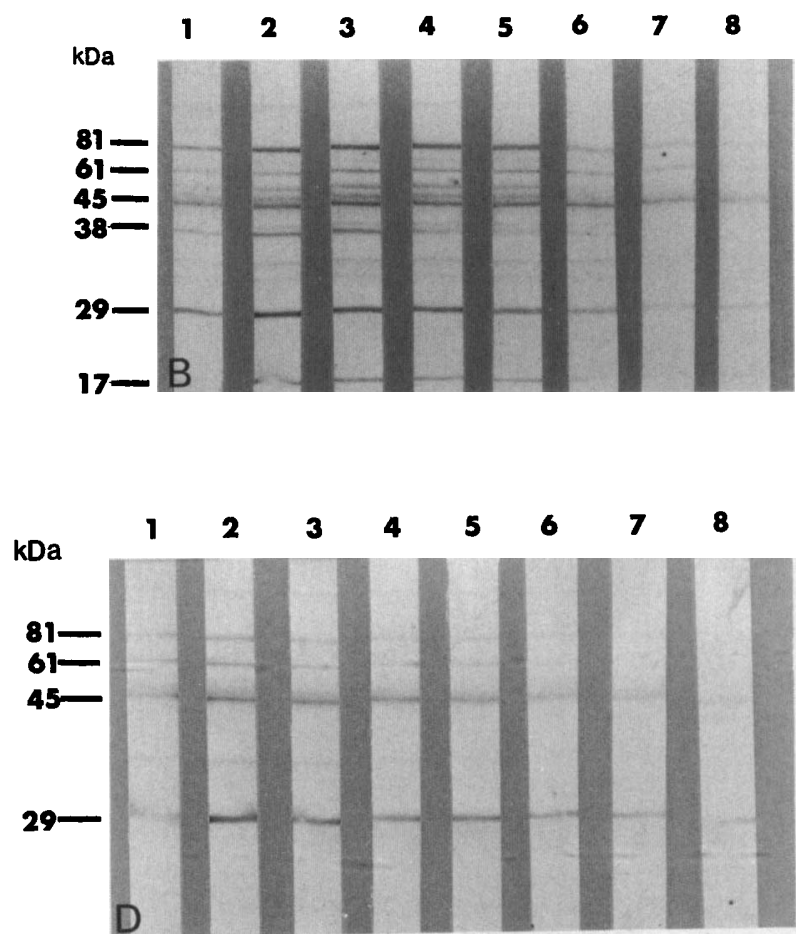

Fig. 3. Strip blots of extracellular proteins (culture supernate) of strain A (i.e., same sample as track 4 of figs. 1 and 2). Replicate strips $1-8$ in each panel were allowed to react with sera diluted 1 in 50,1 in 100,1 in 200,1 in 400,1 in 800,1 in 1600,1 in 3200 and 1 in 6400 respectively; $\mathbf{A}$, pooled human serum; $\mathbf{B}-\mathbf{E}$, sera from patients with $S$. aureus bone infection. 
the pooled normal serum (fig. 3A). The weaker detection of bands with serum diluted 1 in 50 compared with higher dilutions is probably explained by the presence of serum components that interfere with antibody binding at low dilutions. An antigen at $17 \mathrm{kDa}$ was also detected by two of the patients' sera (fig. 3B and E) but not by the other two (fig. 3C and $D$; the marks in the low-mol. wt background of these prints are photographic artefacts).

\section{Discussion}

Our results confirm previous findings that the antibody response of patients with $S$. aureus infection to whole-cell antigens is extremely complex.$^{8,9} \mathrm{Gen}$ erally, the response of serum from infected patients to whole-cell protein antigens revealed by immunoblotting cannot be distinguished from that of uninfected controls,, which reflects the high natural antibody levels in the healthy population. ${ }^{8,9}$ Extracellular antigens of $S$. aureus are easily detected by immunoblotting. ${ }^{6}$ Despite their relatively low concentration, the strength of response to extracellular proteins, which was observed in this study (figs. 1 and 2) emphasises their immunological importance. This is not surprising in view of the wide range of extracellular proteins (including toxins) produced by $S$. aureus and their probable role in infection.

We selected one strain of $S$. aureus from an osteomyelitis infection (strain A) which produced several proteins in the TSB culture supernate. Approximately 11 bands were detected on SDS-PAGE by Coomassie Blue staining. The other strains examined produced some, but not all of these bands and one, the endocarditis isolate (E) produced none. Up to 25

Table. Extracellular proteins produced by $S$. aureus with approximate mol. wts

\begin{tabular}{lcc}
\hline \multicolumn{1}{c}{ Protein } & Mol. wt (kDa) & Reference \\
\hline Coagulase & $30-60$ & 10 \\
Protein A & 42 & 11 \\
Epidermolysins A and B & 30 & 12 \\
Pyrogenic exotoxin A & 12 & 13 \\
Pyrogenic exotoxin B & 18 & 14 \\
*Pyrogenic exotoxin C & 22 & 15 \\
*Toxic shock toxin & 24 & 16 \\
Enterotoxins A-E & $26-30$ & 17 \\
*Enterotoxin F & 20 & 18 \\
$\alpha$ lysin & 36 & 19 \\
$\beta$ lysin & 33 & 19 \\
$\gamma$ lysin & 45 & 19 \\
$\delta$ lysin & $200(?)$ & 19 \\
Leucocidin & 32 & 19 \\
Staphylokinase & $13-15$ & 5 \\
Hyaluronidase & 84 & 5 \\
Nuclease & 16 & 5 \\
Lipase & 100 & 5 \\
Penicillinase & 29 & 5 \\
Acid phosphatase & 58 & 5 \\
& & \\
\hline
\end{tabular}

* These may be the same proteins. different extracellular proteins have been described in S. aureus (table). ${ }^{5,10-19}$

On immunoblotting with serial dilutions of serum, we found that all sera from patients with $S$. aureus bone infection showed high titres of IgG antibodies to the extracellular proteins of strain A. As a group, these sera could be distinguished from sera from uninfected persons, which possessed much lower titres. Serum from patients with deep bone infection due to other organisms was indistinguishable from pooled normal human serum. The difference in response was visible in several of the proteins, most notably the $29-\mathrm{kDa}$ protein. In two of the patients, serum diluted 1 in 6400 still detected this antigen, whereas in control serum it was undetectable at dilutions above 1 in 200. Power et al. ${ }^{4}$ reported a strong response to a low-mol.-wt protein in a rat model of $S$. aureus chronic osteomyelitis. The response was not detected at 3 weeks after infection but became pronounced at 12 weeks. ${ }^{4}$ Their antigen preparation was composed of crude cell walls but, presumably, could have contained some extracellular protein associated with the wall prior to release. This is consistent with our results which showed that rabbit antiserum raised against washed, killed whole cells detected extracellular antigen.

We have not attempted to identify any of the antigen bands at present but presume that, as extracellular products, they are readily detected by the immune system after release from the organisms at the site of infection in the bone. The biofilm mode of growth associated with such infections ${ }^{20}$ may obstruct release of whole-cell antigenic material, whilst permitting release of extracellular antigens. However, data confirming this are not available.

Detection of deep infection in bone is of great clinical significance in several situations. In particular, it is very important to distinguish septic from mechanical loosening of a prosthesis as the treatment of the two conditions is different. Antibody response to extracellular antigens seems promising as a simple, non-invasive method of detecting deep bone infection; however, further work with far larger numbers of sera is required to determine its sensitivity and specificity. Accuracy may be improved by blotting serum from a patient against antigens derived from his or her own organism if one has been obtained previously.

Comparison of serum samples obtained from a single patient over a period of time may make it possible to monitor response to treatment, or to diagnose recrudescence of infection. This principle has been applied to Pseudomonas aeruginosa infection in cystic fibrosis. ${ }^{21}$

If the serological response to the extracellular proteins we have identified is sufficiently discriminatory, it may be more practical to replace immunoblotting by an ELISA assay. The protein antigens are produced in sufficient quantities to be recovered from TSB culture supernates and purified.

We have so far worked only with extracts from $S$. aureus, but there is no reason, in principle, why 
similar techniques could not be applied to other clinically important organisms such as coagulasenegative staphylococci. Previous work has demonstrated the potential of immunoblotting as a sensitive serodiagnostic test for infective endocarditis due to Enterococcus faecalis. ${ }^{22}$ It may eventually be possible, if specific ELISA preparations can be developed for

\section{References}

1. Wergeland HI, Haaheim LR, Natas OB, Wesenberg F, Oeding P. Antibodies to staphylococcal peptidoglycan and its peptide epitopes, teichoic acid, and lipoteichoic acid in sera from blood donors and patients with staphylococcal infections. J Clin Microbiol 1989; 27: 1286-1291.

2. Cheung AL, Bayer AS, Peter J, Ward JI. Surface proteins of Staphylococcus aureus. Rev Infect Dis 1988; 10 Suppl 2: S351-S355.

3. Thomas VL, Sanford BA, Keogh BS, Triplett RG. Antibody response to Staphylococcus aureus surface proteins in rabbits with persistent osteomyelitis after treatment with demineralized bone implants. Infect Immun 1989; 57 : 404-412.

4. Power ME, Olson ME, Domingue PAG, Costerton JW. A rat model of Staphylococcus aureus chronic osteomyelitis that provides a suitable system for studying human infection. J Med Microbiol 1990; 33: 189-198.

5. Arvidson SO. Extracellular enzymes from Staphylococcus aureus. In: Easmon CSF, Adlam C (eds) Staphylococci and staphylococcal infections. London, Academic Press. 1983; 2: 745-808.

6. Krikler SJ, Pennington TH, Petrie D. Typing of strains of Staphylococcus aureus by Western blot analysis of culture supernates. J Med Microbiol 1986; 21: 169-171.

7. Lugtenberg B, Meijers J, Peters R, Van der Hoek P, Van Alphen L. Electrophoretic resolution of the 'major outer membrane protein' of Escherichia coli K12 into four bands. FEBS Lett 1975; 58: 254-258.

8. Espersen F, Schiøtz PO. Normally-occurring precipitating antibody against Staphylococcus aureus in human serum and colostrum. Acta Pathol Microbiol Scand Sect C 1981; 89: 93-98.

9. Bell JA, Pennington TH, Petrie DT. Western blot analysis of staphylococcal antibodies present in human sera during health and disease. $J$ Med Microbiol 1987; 23: 95-99.

10. Jeljaszewicz J, Switalski LM, Adlam C. Staphylocoagulase and clumping factor. In: Easmon CSF, Adlam C (eds) Staphylococci and staphylococcal infections. London, Academic Press. 1983 ; 2: 525-527.

11. Björk I, Petersson BA, Sjöquist J. Some physiochemical several organisms, to obtain within hours serological confirmation of deep infection by a particular bacterial species.

Other authors have concentrated on cellular antigens, but this study demonstrates the immunological importance and potential of extracellular antigens. properties of protein A from Staphylococcus aureus. Eur J Biochem 1972; 29: 579-584.

12. Arbuthnott JP. Epidermolytic toxins. In: Easmon CSF, Adlam C (eds) Staphylococci and staphylococcal infections. London, Academic Press. 1983; 2: 599-617.

13. Schlievert PM, Schoettle DJ, Watson DW. Purification and physicochemical and biological characterisation of a staphylococcal pyrogenic exotoxin. Infect Immun 1979; 23 609-617.

14. Schlievert PM. Purification and characterization of staphylococcal pyrogenic exotoxin type B. Biochemistry 1980; 19: 6204-6208.

15. Schlievert PM, Shands KN, Dan BB, Schmid GP, Nishimura RD. Identification and characterization of an exotoxin from Staphylococcus aureus associated with toxic-shock syndrome. J Infect Dis 1981; 143: 509-516.

16. Igarashi $H$, Fijikawa $H$, Usami $H$, Kawabata $S$, Morita $T$. Purification and characterization of Staphylococcus aureus FRI 1169 and 587 toxic shock syndrome exotoxins. Infect Immun 1984; 44: 175-181.

17. Bergdoll MS. Enterotoxins. In: Easmon CSF, Adlam C (eds) Staphylococci and staphylococcal infections. London, Academic Press. 1983; 2: 559-598.

18. Bergdoll MS, Crass BA, Reiser RF, Robbins RN, Davis JP. A new staphylococcal enterotoxin, enterotoxin $F$, associated with toxic-shock-syndrome Staphylococcus aureus isolates. Lancet 1981; 1 : 1017-1021.

19. Mollby R. Isolation and properties of membrane damaging toxins. In: Easmon CSF, Adlam C (eds) Staphylococci and staphylococcal infections. London, Academic Press. 1983; 2: $619-669$.

20. Mayberry-Carson KJ, Tober-Meyer B, Smith JK, Lambe DW, Costerton JW. Bacterial adherence and glycocalyx formation in osteomyelitis experimentally induced with Staphylococcus aureus. Infect Immun 1984; 43: 825-833.

21. Høiby N, Flensborg EW, Beck B, Friis B, Jacobsen SV, Jacobsen L. Pseudomonas aeruginosa infection in cystic fibrosis. Diagnostic and prognostic significance of Pseudomonas aeruginosa precipitins by means of crossed immunoelectrophoresis. Scand J Respir Dis 1977; 58: 65-79.

22. Shorrock PJ, Lambert PA, Aitchison EJ, Smith EG, Farrell ID, Gutschik E. Serological response in Enterococcus faecalis endocarditis determined by enzyme-linked immunosorbent assay. J Clin Microbiol 1990; 28: 195-200. 